\title{
Saving Water while Enhancing Transplanting Success of Pinus halepensis
}

\author{
Syropli Aik ${ }^{1}$ and Iakovoglou $\mathrm{V}^{2 *}$ \\ ${ }^{1}$ MSc in Water Resources, International Hellenic University (IHU), Greece \\ ${ }^{2}$ UNESCO Chair Con-E-Ect, Conservation and Ecotourism of Riparian and Deltaic Ecosystems, International Hellenic University (IHU), Greece
}

Submission: April 26, 2021; Published: May 24, 2021

*Corresponding author: Iakovoglou V, International Hellenic University, Drama 66100, Greece

\section{Abstract}

Mediterranean ecosystems are of high ecological importance, mainly due to their increased biodiversity levels. Nonetheless, restoring them is a hard task, mainly due to the semi-arid climate that prevails particularly during summer months. The aim of this study was to observe the effect of drought preconditioning of three-year-old P.halepensis seedlings in order to produce better equipped seedlings for restoration purposes. The hypothesis was that water deficit conditions induce physiological cues that enhance characteristics such as Root Growth Potential (RGP) that help seedlings for further water and nutrient exploitation. The seedlings were subjected for one month under three irrigation frequency treatments; watering twice per week, once per week and once per two weeks. At the end of a month, they were evaluated for characteristics, such as height and RGP. The results revealed that the seedlings that were watered more frequently had increased growth, while the seedlings that were watered the least had greater RGP. Therefore, the species of P.halepensis under water deficit conditions invest in the development of new roots that enable the species to survive and tolerate the semi-arid Mediterranean Greek ecosystems. Consequently, the benefit is dual; saving water while preconditioning seedlings to enhance growth traits like root growth that enhance transplanting success.

Keywords: Biodiversity; Conservation; Ecophysiology; Preconditioning; Restoration; Seedling production

\section{Introduction}

Mediterranean ecosystems are of high ecological value mainly due to their increased biodiversity levels. Despite their importance, their restoration is a hard task that relates to the prevailing semi-arid climate [1-3]. The stressed water deficit condition that plants experience, particularly during the hot-dry summers, is the main factor that negatively affects the survival and welfare of the transplanted seedlings [4]. Due to climate change, the intensity and frequency of aridity becomes more profound for the Mediterranean region [4,5]. As a result, restoration and reforestation efforts increasingly fail.

One of the methods used by forest nurseries to enhance transplanting success is preconditioning [6-8]. Specifically, seedlings undergo a period of stressed growth conditions prior to transplanting. This triggers physiological cues that enhance growth traits that help seedlings successfully establish under field conditions [8]. One of the growth traits is the ability to produce new roots. For the semi-arid ecosystems, drought preconditioning works as a signal for the seedlings to produce new roots in order to tolerate post-planting drought conditions [4,9]. "Root Growth Potential, RGP" is a useful tool to assess the quality of the seedlings and their ability to develop new roots $[10,11]$. Research showed that RGP was positively correlated with seedling viability as well as the above ground seedling biomass development under field conditions $[6,7,10-14]$. So, the estimation of RGP provides a good surrogate on the ability of the species to grow new roots for water and nutrient exploitation.

Pinus halepensis Mill. (Aleppo pine) [15], is a thermophilic species that can tolerate high temperatures and drought growth conditions. It covers 2.5 million hectares at the western Mediterranean region in areas such as Albania, Israel and Greece [16]. It usually dominates coniferous fire prone forests ecosystems. It has a wide distribution range at the western Greek areas at an altitudinal variation between 0 to $600 \mathrm{~m}$ [17]. Due to its wide spread and ability to dominate and grow under semi-arid climatic conditions, $P$. halepensis is highly used for reforestation and restoration purposes [18].

Consequently, the study is aiming to investigate seedling responses of $P$. halepensis that have undergone a preconditioning period of irrigation treatments. It was hypothesized that seedlings that experience reduced water conditions would have increased ability to develop new roots for further water and nutrients exploitation in order to successfully establish on a site. By 
studying seedling behavior under water stress conditions, we are able to mimic field conditions and determine the best irrigation frequency prior to transplanting to increase the percent of survival. Therefore, the benefit is dual; saving water by reducing the irrigation frequency while increasing the transplanting success.

\section{Material and Methods}

Three-year-old seed-derived seedlings were grown under field conditions in $55 \times 60 \times 160 \mathrm{~cm}$ (QuickPot QP 24T/16) containers filled with standard soil substrate mixture (peat, perlite, fertilizer, $10 \%$ soil) at the forest nursery of Chalkidona, Greece. For experimental purposes, seedlings were placed in a controlled growth chamber under light of high-pressure sodium lamps (PPFD $300 \mu \mathrm{mol} \mathrm{m} \mathrm{m}^{-2} \mathrm{~s}^{-1}$ ) for photoperiod of 14 hours and room temperature of $21 \pm 2^{\circ} \mathrm{C}$. The Root Growth Potential (RGP) was estimated as described by Mattson's methodology [11]. The seedlings were placed in stainless steel trays with soil substrate 1(peat):1(sand) that enabled the development of new roots. The trays were placed in a water bath with controlled temperature of $21 \pm 2^{\circ} \mathrm{C}$ and room humidity of $40 \pm 10 \%$.

According to the experimental design, three were the irrigation frequency treatments: watering twice per week, watering once per week and watering once per two weeks. The "control" referred to seedlings that were evaluated prior to the initiation of the experiment. All treatments were selected based reduced watering levels compared to the "daily irrigation frequency" that is used by forest nurseries under field conditions. After the irrigation treatment, the excess water was pumped up from the trays through a pipe, while there was no application of fertilizers. At the end of the experimental month, the seedlings were extracted from the trays and carefully cleaned. For each irrigation treatment five seedlings were used for evaluation.

Specifically, the height (HT) and the root collar width (RCW) were evaluated with a digital caliper and the leaf area (LA) was measured with a special leaf area instrument (Portable Area Meter, LI- 3000C). The dry weights of the seedling's subparts were also estimated by cutting and placing them in an oven for 72 hours at $80^{\circ} \mathrm{C}$ [19]. Specifically, the leaf dry weight (LDW), the shoot dry weight (SDW), the total root dry weight (TRDW), the total dry weight above ground seedling parts (TDWup) and the total seedling dry weight (TSDW) were measured. The RGP was evaluated based on the new roots dry weight (NRDW) and the maximum new root length (MaxNRL). The Specific Leaf Area (SLA, ratio of leaf area/dry weight of leaves) was also estimated [20], as well as the ratio (RATIO) of the total root dry weight by the total dry weight above ground seedling parts (TRDW / TDWup) [21].

For the statistical analysis one-way ANOVA was used to compare means among irrigation treatments for each studied variable, with data been tested for normality and homogeneity [22]. Mean differences were compared with the Tukey's multiple range tests at the significance levels of $p<0.05$.

\section{Results and Discussion}

Based on the study, the results indicated different growth responses among the three irrigation frequencies treatments. Overall, the seedlings that received more frequent irrigation (twice or once a week) had a greater development than the seedlings that were watered the least (once every two weeks). However, the least watered seedlings had greater development of new roots.
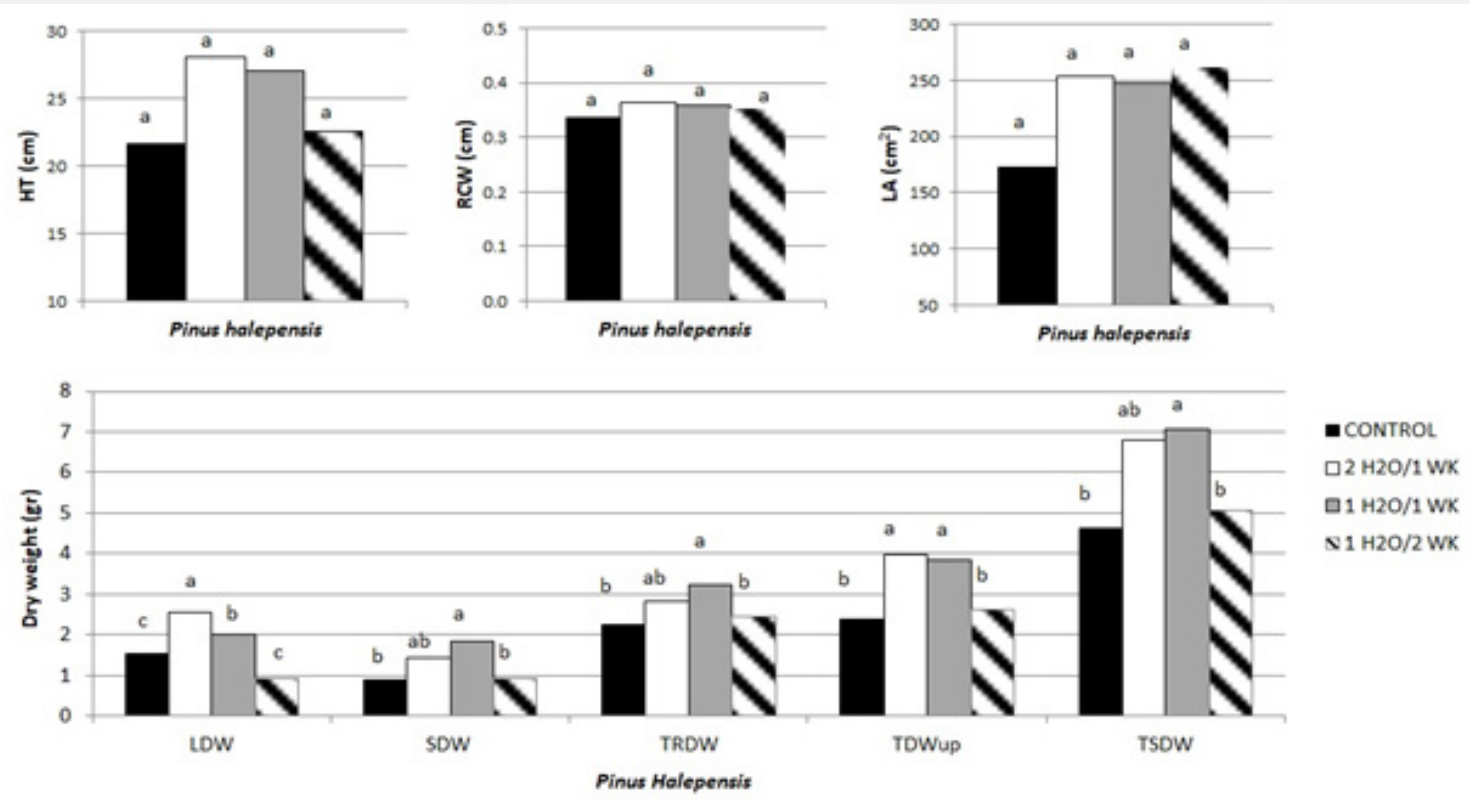

Figure 1: Seedling performance of $P$. halepensis based on irrigation frequency treatments for the variables of HT, RCW, LA and dry weights for LDW, SDW, TRDW, TDWup and TSDW. 
Further, the HT, the RCW and the LA did not indicate differences among the irrigation treatments (Figure 1). Consequently, those variables didn't show any immediate seedling response for the evergreen species of $P$. halepensis based on the irrigation treatments for the experimental period of a month. The effect was more profound by the biomass partitioning of the seedlings' subparts based on their dry weights. Specifically, the seedlings that were watered once or twice per week had the greatest growth above and below ground; specifically the LDW, SDW, TRDW,
TDWup and TSDW (Figure 1). Similar results were found for one year P. halepensis [4] as well for the species of Myrtus communis [23], with reduced irrigation treatments having decreased root biomass. Based on this study, three-year-old seedlings of $P$. halepensis maintain their growth even under the reduced irrigation frequency of one watering per week. Consequently, the amount of water that can be saved is tremendous while also maintaining its physiological welfare.
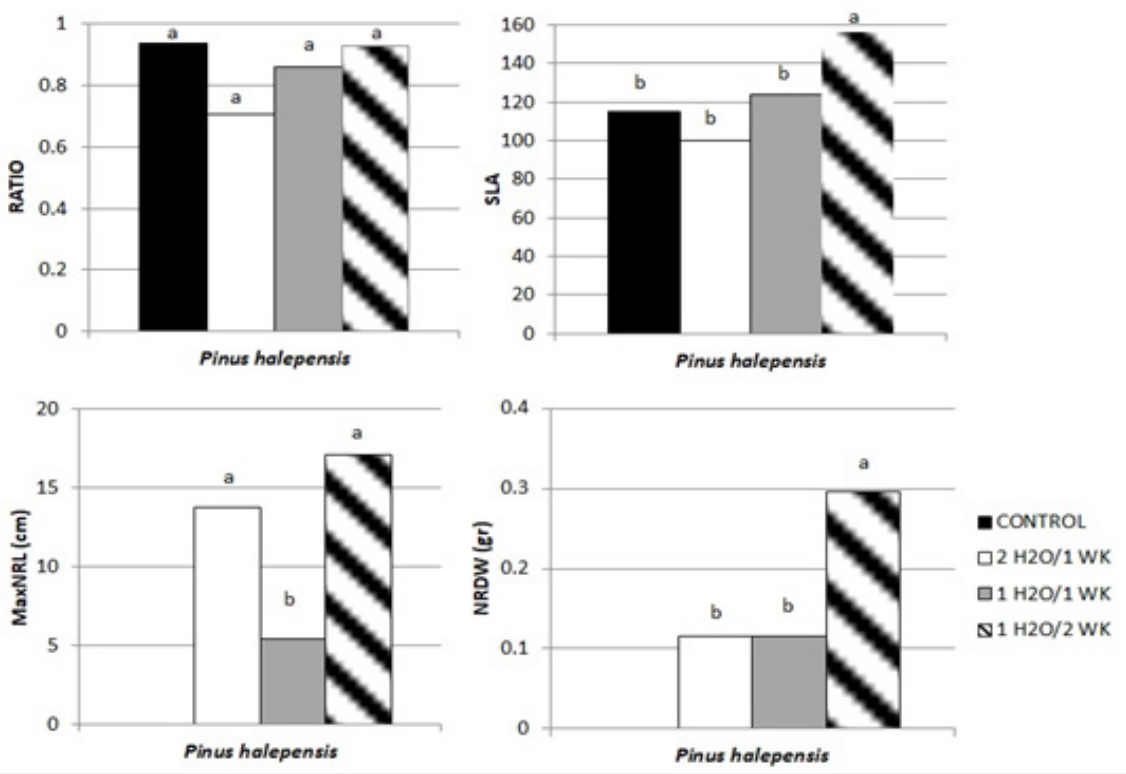

Figure 2: Seedling performance of $P$. halepensis based on irrigation frequency treatments for the variables of RATIO (root to shoot dry weight), SLA (leaf area to leaf dry weight) and RGP as determined by the MaxNRL and the NRDW.

Further, although the RATIO did not indicate differences among treatments, the SLA was greater for seedlings that were watered once every two weeks (Figure 2). These findings differentiate from other studies that showed that species experiencing water stress conditions were associated with lower SLA values; therefore, they had thicker leaves $[21,24]$. In this study, despite that the LA did not differ among irrigation treatments, the LDW showed the least dry weight for the seedlings that experienced the most water stress (one irrigation per two weeks). That could be the result of reduced leaves due to leaf abscission as a physiological response in order for the species to cope with water deficit conditions (experimental observation).

According to the RGP, both the NRDW and MaxNRL were greater for the seedlings that were subjected at the least irrigation frequency of one watering every two weeks (Figure 2). So, although those seedlings received the least water and had the least above ground biomass accumulation, they had the greatest RGP. Therefore, the experimental preconditioning period of one month of one irrigation every two weeks was adequate to induce a metabolic shift towards the development of new roots at the expense of the rest of the seedling growth traits, such as leaf production. Therefore, this suggests that one of the physiological mechanisms of $P$. halepensis that enhance its survival in semiarid environments like Greece, is their fast metabolic shift towards the production of a new roots for further water and nutrient exploitation. In terms of conserving water, the benefit is tremendous by watering only twice a month. Consequently, both saving water while preconditioning seedlings to enhance growth traits like root development that enhance transplanting success [25].

\section{Conclusion}

According to the results, the seedlings of $P$. halepensis that were exposed under water deficit conditions were able to maintain their growth. The seedlings with the least water frequency had greater SLA and RGP (as indicated by NRDW and MaxNRL). These results show that the seedlings of $P$. halepensis invested in the development of new roots for further exploitation of water and nutrients for their survival. This could be one of the main characteristics that enable the species to dominate the semi-arid areas of Greece; it triggers cues for further root growth. Undoubtably, we benefit by both saving water and preconditioning to produce better equipped seedlings for successful transplant.. 


\section{References}

1. Rudel Ph (2007) Mediterranean climate ecosystems. Encyclopedia of biodiversity $3: 1-15$.

2. Castro J, Zamora R, Hódar JA, Gómez JM (2004) Seedling establishment of a boreal tree species (Pinus sylvestris) at its southernmost distribution limit: consequences of being in a marginal Mediterranean habitat. Journal of Ecology 92(2): 266-277.

3. Mentoza I, Zamora R, Castro J (2009) A seedling experiment for testing tree community recruitment under variable environments: Implications for forest regeneration and conservation in Mediterranean habits. Biological Conservation 142(7): 1491-1499.

4. Villar Salvador PV, Ocaña L, Peñuelas J, Carrasco I (1999) Effect of water stress conditioning on the water relations, root growth capacity, and the nitrogen and non-structural carbohydrate concentration of Pinus halepensis Mill. (Aleppo pine) seedlings. Annals of Forest science 56(6): 459- 465.

5. Lionello P, Rizzoli M, Boscolo R, Alpert P, Artale V, et al. (2006) The Mediterranean climate: an overview of the main characteristics and issues. Dev Earth Environ Sci 4: 1-26.

6. Larsen HS, South DB, Boyer JM (1986) Root growth potential, seedling morphology and bud dormancy correlate with survival of loblolly pine seedlings planted in December in Alabama. Tree physiology 1(3): 253263.

7. Jenkinson, JL (1980) Improving plantation establishment by optimizing growth capacity and planting time of western yellow pines. USDA Forest Service. PSW 15: 22

8. Iakovoglou V, Halivopoulos G (2016) Ecophysiology responses of Preconditioning of Forest Species. A Review. Journal of Engineering Science and Technology Review 9(1): 7-11.

9. Puértolas J, Gil L, Pardos JA (2003) Effects of nutritional status and seedling size on field performance of Pinus halepensis planted on former arable land in the Mediterranean basin. 1 Forestry 76(2): 159.

10. O Reilly C, Harper C, Keane M (2002) Influence of physiological conditions at the time of lifting on the cold storage tolerance and field performance of ash and sycamore. Forestry 75(1): 1-12.

11. Mattsson A (1986) Seasonal variation in root growth capacity during cultivation of container grown Pinus sylvestris seedlings. Scandinavian Journal of Forest Research 1(1-4): 473-482.

12. Garriou D, Girard S, Guehl JM, Genere B (2000) Effect of desiccation during cold storage on planting stock quality and field performance in forest species. Annals of Forest Science 57(2): 101-111.
13. Pardos M, Royo A, Gil L (2003) Effect of nursery location and outplanting date on field performance of Pinus halepensis and Quercus ilex seedlings. Forestry 76(1): 67-81.

14. Schier GA (1970) Seasonal pathways of 14C-photosynthate in red pine labelled in May, July and October. Forest Science 16(1): 2-13.

15. Tapias R, Climent J, Gil L (2004) Life histories of Mediterranean pines. Plant Ecology 171: 53-68.

16. Rigolot E (2004) Predicting postfire mortality of Pinus halepensis Mill. and Pinus pinea L. Plant Ecology 3(1-2): 139- 151.

17. Dimitrakopoulos AP, Mitsopoulos ID, Kaliva A (2011) Short communication. Comparing flammability traits among firestricken (low elevation) and non fire-stricken (high elevation) conifer species of Europe: a test of the Mutch hypothesis. Forest Systems 22(1): 134-137.

18. Rouo A, Gil L, Pardos J (2001) Effect of water stress conditioning on morphology, physiology and field performance of Pinus halepensis Mill. seedlings. New forests 21(2): 127-140.

19. Wilson JP, Thomson K, Hodson GJ (1999) Specific leaf area and leaf dry matter content as alternative predictors of plant strategie. New Phytology 143(1): 155-162.

20. Garnier E, Shipley B, Roumet C, Laurent G (2001) A standardized protocol for the determination of specific leaf area and leaf dry matter content. Functional Ecology 15(5): 688-695.

21. Lloret F, Casanovas C, Penuelas J (1999) Seedlings survival of Mediterranean shrubland species in relation root: shoot ratio, seed size and water and nitrogen use. Functional Ecology 13(2): 210-216.

22. SPSS (2006) Rel. 15.0, Brief guide, SPSS, Chicago, p .191.

23. Iakovoglou V, Kokkinou E (2018) Response of Myrtus communis seedlings under irrigation frequencies. International Journal of Bioresource and Stress Management 9(1): 069-074.

24. Amanullah JH, Muhammad N, Khalid, Asad A (2007) Response of Specific Leaf Area (SLA), Leaf Area Index (LAI) and Leaf Area Ratio (LAR) of Maize (Zea mays L.) To Plant Density, Rate and Timing of Nitrogen Application. World Applied Sciences Journal 2(3): 235-243.

25. Chaves MM, Pereira JS, Maroco J, Rodrigues ML, Ricardo CPP, et al. (2002) How plants cope with water stress in the field? Photosynthesis and growth. Annals of Botany 89(7): 907-916.

Your next submission with Juniper Publishers will reach you the below assets

- Quality Editorial service

- Swift Peer Review

- Reprints availability

- E-prints Service

- Manuscript Podcast for convenient understanding

- Global attainment for your research

- Manuscript accessibility in different formats

( Pdf, E-pub, Full Text, Audio)

- Unceasing customer service

Track the below URL for one-step submission https://juniperpublishers.com/online-submission.php 